\title{
Inheritance of Abdominal Fat in Egg Layers
}

\author{
M. Farghaly, M.M. Ali, M.A. Asar and G. El-Sharrawi \\ Department of Animal Production, Faculty of Agricul- \\ ture University of Alexandria, Alexandria, Egypt.
}

\begin{abstract}
BASED on sire components, the heritability estimates for live body weight, abdominal fat weight and egg number laid during the first 90 days of laying were $.89, .61$ and .17 , respectively. There was a negative correlation between live body weight and number of eggs laid. Abdominal fat weight was closely positively correlated with live body weight, and negatively correlated with number of eggs laid and dressing percentage.
\end{abstract}

These results suggest that selection should be practiced against abdominal fat during the laying period in females. However, selection for decreased amount of abdominal fat would probably reduce body weight, with a possible correlated effect on egg weight.

KEY WORDS (Inheritance, abdominal fat, egg layers)

There is quite a lot of studies on the inheritance of abdominal fat in chickens. Differences in fat deposition between breeds (Edwards and Denman, 1975) and strains within breeds (Ehinger and Seemann, 1982) indicate the importance of genetic factors in fat deposition.

Several estimates of the heritability of abdominal fat have been published. A genetic variation within strain in the total amount of fat was found by Friars et al. (1983). They estimated the heritability of total percentage body fat to be 0.48 . Gyles et al. (1984) reported the heritability of the absolute amount of abdominal fat was 0.67 in males and 0.24 in females calculated from sire component In the experiment of Friars et al. (1983) the degree of heritability estimated from the dam component of variance is higher than that estimated from the sire component. 
On the other hand, Ricard and Rouvier, 1967 and 1969 found that the heritability estimated from the sire component of variance is considerably higher than that estimated from the dam component.

The phenoiypic correlations between live body weight and absolute amount of abdominal fat was 0.55 in females (Friars et al., 1983). The corresponding value between live body weight and abdominal fat as percentage of body weight was 0.18 .

This study was conducted to estimate the heritability of live body weight, abdominal fat and some other traits in laying hexis, to calculate the phenotypic correlations between the various traits and to assess the value of using abdominal fat traits, age at first egg, oviduct length and width of pubic bones to predict egg number.

\section{MATERIAL and METHODS}

The data used in this study were obtained from the flock of Alexandria chickens maintained at the Alexandria University, Poulry Research Center. In the 1984 breeding season, twelve individual male breeding pens were made up by assigning one male at random to each pen and likewise allotting from 9 to 10 females to each pen. A total 1265 of chicks were produced in three consecutive hatchs. A hatch consisted of eggs collected over a 2-week interval. All pullets were reared to five months of age in floor pens and fed the standard University of Alexandria growing ration to 8-week of age and the standard rearing ration from 8 to 20 weeks of age. They were then placed in individual cages and provided with the University of Alexandria laying ration. All diets and water were available ad inbitum. .....

Age at sexual maturity was assessed as the age in days at first egg and daily egg production records were obtained during the first 90 days of laying for each hen.

A total of 130 hens from 32 dams and 6 sires were used in this study. When the birds were 14 months of age the live body weight was obtained and the width of pubic bones was measured. They were then slaughtered according to Islamic regulation by cutting the jugular vein across the throat at the base of the skull by a sharp knife. The feathers were manually. removed. Weights of the warm eviscerated carcasses including the neck but

Egypt J. Anim. Prod. 26, No. 1. (1986) 
excluding the giblets (gizzard, heart and liver) were taken. The abdominal fat surrounding the g.zzard and that whin lay between the abdominal muscles and the intestines were removed and weighed. The leng h of oviduc without vagina was measured. The actual we ghts of abdominal fat, eviscerated carcass and giblets expressed as a percentage of live weight were computed.

Before sutistical analysis, percentages were subjected to aresine transformation in accordance with Sredecor and Cochran (1967).

The estimates of herifability for all traits wore determined by means of the variance component, analysis following the method outlined by Becker (1968) for the one way nested classification. The statistical model for the component analysis was

$$
\mathrm{X}_{\mathrm{ix}}=\mathrm{U}+\mathrm{S}_{\mathrm{i}}+\mathrm{e}_{\mathrm{ik}}
$$

where $\mathrm{X}_{\mathrm{ik}}$ is the measurement of a trait on the $\mathrm{k}^{\mathrm{it}}$ bird of the $\mathrm{i}^{\mathrm{k}}$ sire, $\mathrm{U}$ is the overall mean of the population,

$S_{1}$ is the effect of the $\mathrm{i}^{\text {th }}$ sire, and

$\mathrm{e}_{\mathrm{i} k}$ is the random error.

All terms in the model except $U$ were assumed to be random. Heritability was estimated from the formula

$$
\mathrm{h}^{2}=\frac{4 \mathrm{O}_{\mathrm{s}}^{-2}}{\mathrm{O}_{\mathrm{S}}^{-2}+\mathrm{O}_{\mathrm{W}}^{-2}}
$$

Phenotypic correlations between various traits were calculated. Multiple regression analysis was used to assess the value of using abdominal fat weight $\left(\mathrm{X}_{1}\right), \%$ abdominal fat/live weight $\left(\mathrm{X}_{*}\right)$, age at first egg $\left(\mathrm{X}_{3}\right)$, oviduct length $\left(X_{i}\right)$ and width of pubic bones $\left(X_{s}\right)$ to predict egg number. All the computations were earried out using a Hewlett Packrd Computer at the Faculty of Agriculture Computer Unit.

\section{Results and Discussion}

Means, standard errors and coefficients of variation for studied traits are given in Table 1. The coefficient of variation in abdominal fat weight was high $(53.4 \%)$, perhaps because of the manual removal of the abdominal fat by two operators. Expressing abdominal fat weight as percentage of body weight decreased the coefficient of variation. 
TABLE 1. Means (X') standard errors (S.E.) and coefficients of variation (C.V) for studied trais.

\begin{tabular}{|c|c|c|c|c|}
\hline$T=a t t$ & $\begin{array}{l}\text { Number } \\
\text { of birds }\end{array}$ & $\ldots=$ & $S, 2$ & $5 . \mathrm{v}$ \\
\hline itve wotght & 130 & 28.26 .1 & 52.1 & $32=$ \\
\hline fodominal fat weight (g) & 130 & 53.9 & 2.5 & 53.4 \\
\hline Atocounal iat/live welght (g) & 130 & 2.4 & 0.1 & $17=$ \\
\hline Curcass wedght/Alur wetght (q) & 130 & 61.8 & 1.9 & 1.4 : \\
\hline 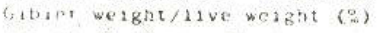 & 130 & 11.3 & C. 1 & 16. 1 \\
\hline A2l at f2rot egg (day) & 130 & 176.4 & 0.8 & 32 \\
\hline EgR number to 90 days (egg) & 130 & 53.9 & 1.0 & 21.1 \\
\hline Lestigth of the oviduct $(\mathrm{CD})$ & 130 & 34.1 & 0.6 & 105 \\
\hline 1.1dth of pubilc bores (cai) & 130 & 4.5 & 0.1 & 25.2 \\
\hline
\end{tabular}

In broilers, the coefficient of variation of amount of abdominal fat is 25 to $30 \%$, while the coefficient of variation of the total fat content (abdominal fat included) varies between 15 and $20 \%$ (Leenstra, 1984).

Heritability estimates from the analysis of variance are given in Table 2. The heritability estimate for live body weight was high (.89). This estimate is higher than the .27 estimate of Shebl (1986) who worked on the same flock.

Heritability of abdominal fat weight was .61 which is somewhat lower than but in the range of the .70 estimate of Ricard and Rouvier (1969) calculated from sire component for abdominal fat in 59-day old Cornish chicken. However, it is higher than .32 and .24 estimates of Friars et al. (1983) and Gyles et al. (1984) in broiler females. The high heritability suggest it may be possible to select for or against abdominal fat in laying hens. The amount of abdominal fat relative to body can be reduced by selection through progeny testing or sib selection (Leclercq et al., 1980), selection for feed efficiency (Pym and Solvyns, 1979) and selection based on the concentration of triglycerides in blood plasma (Griffin and Whitehead, 1982).

Phenotypic correlation coefficients between traits are given in Table 2 . The correlation between live body weight and abdominal fat weight was .47 but decreased to a non-significant value when abdominal fat was expressed

Egypt J. Anim. Prod. 26, No. 1. (1986) 


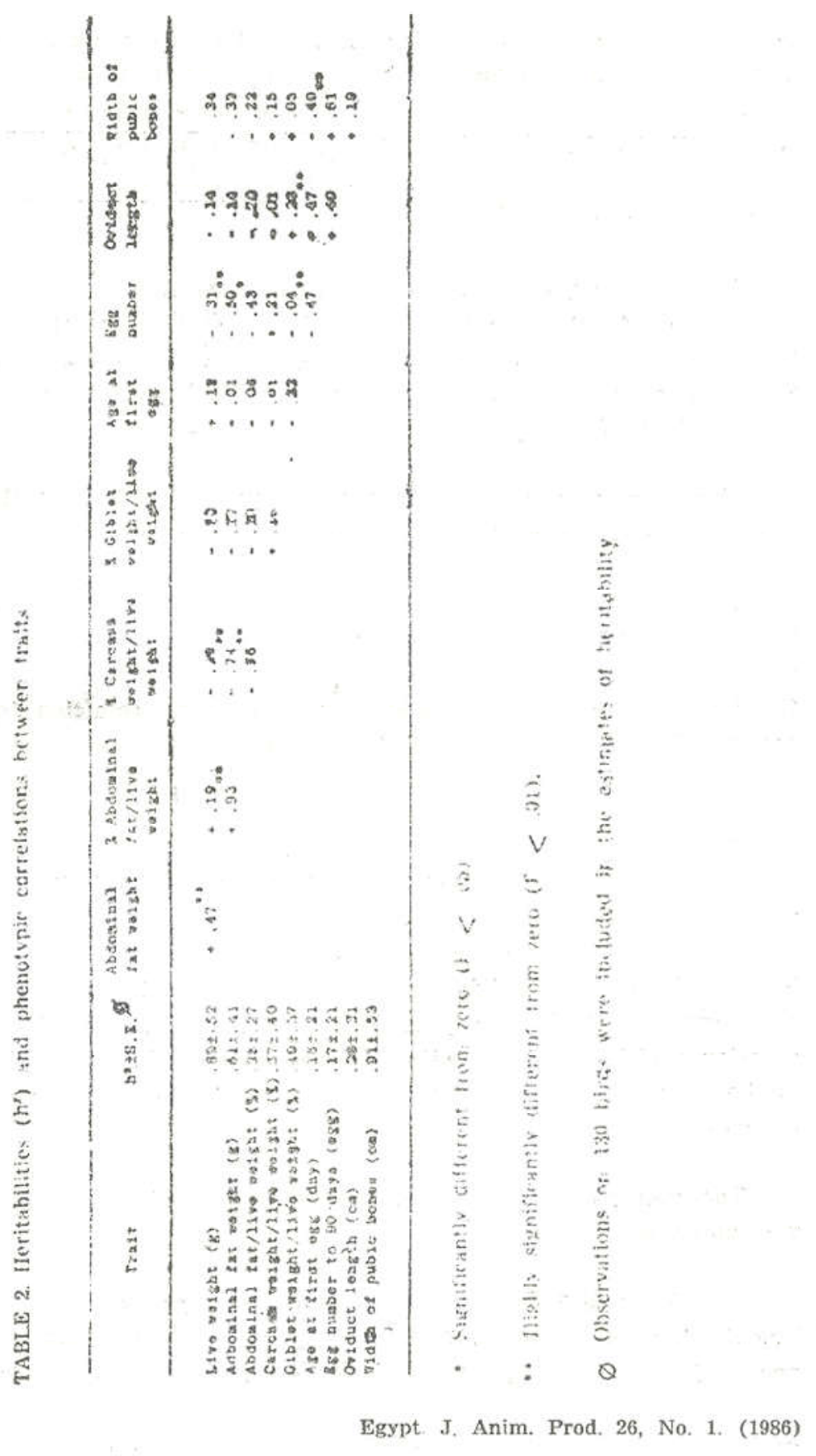


as percentage of live weight. The same results were reported by Friars et al. (1983). Gyles et $a l_{*}$ (1982) found a highly significant $(\mathrm{P} \leqslant .01)$ positive correlations between body weight and the three measures of fatness (fat weight, $1 \%$ fat/live weight and $\%$ fat/cárcass weight). Ricard and Rouvier (1969) found phenotypic correlation between body weight and abdominal fat in female chickens to be .41 .

There was a negative phenotypic correlation between live weight of adult females and numbers of eggs laid in the first 90 days of laying. However, Shebl (1986) found a positive phenotypic correlation (.25) between live weight of females at age at sexual maturity and number of eggs laid in the first 90 days of laying.

There was a highly significant $(P \leqslant .01)$ negative correlation between number of eggs to 90 days and abdominal fat weight.

These results suggest that selection should be practice against abdominal fat during the laying period in females. The purpose of this selection would be to decrease abdominal fat, increase egg production and increase the feed efficiency of egg production. However, selection for decreased amount of abdominal fat would probably reduce body.weight with a possible correlated effect on egg weight.

The regression equation of abdominal fat on live weight was :

where

$$
\ldots \mathrm{Y}_{1}:=34.45+0.48 \mathrm{X}\left(\mathrm{r}^{2}=0.23\right)
$$

$Y_{2}=$ abdominal fat weight $(g)$ and $X=$ live body weight $(g)$. A signifi cant regression coefficient is an indication that abdominal fat should be regression coefficient is an indication that abdominal fat should be regressed on body weight when comparing diets, strains, or other experimental procedures.

The multiple regression equation of egg number on the independent variables was :

$$
\mathrm{Y}_{i}=56.714-.137 \mathrm{X}_{1}+.426 \mathrm{x}_{\mathrm{s}}-.20 . \mathrm{x}_{i}+6.397 \mathrm{X}_{5}
$$

Egg number was significantly influenced $(\mathrm{P} \leqslant .01)$ by width of pubic bones, age at first egg, oviduct length and abdominal fat weight. $R^{2}$, the amount

Egypt. J. Anim. Prod. 26, No. 1. (1986) 
of variability in abdominal fat weight as explained by these four independent variables was 0.61 . Based on the results of the multiple regression equation, width of pubic bones may be a better prediction of egg number than the other independent varaibles.

\section{References}

Becker, W.A. (1968), «Manual of Procedures in Quantitative Genetics», 2nd edn. Wash. State. Univ. Press. Pullman.

Edward, Jr. H.M, and Denman F. (1975). Carcass composition studies. 2. Influences of breed, sex and diet on gross composition of the carcass and fatty acid com position of the adipose tissuc. Poultry Sci 54; 1230-1238

Ehinger, F. and G. Seemann (1982). Einfluss von Futter, Alter und Geschlecht auf Mastleistung und Schlachkörperqualität von Broilern verschiedener Herkunft. 2. Verfettungsgrad. Archiv fur Geflügelkunde $46: 177-188$.

Friars, G W., C.Y. Lin, D.L. Patterson and L.N. Irwin (1983). Genetic and phenotypic parametrs of fat deposition and associated trats in Broilers. Ponltry Sci. 62 : 1425.

Griffin, HD. and C.C. Whitehead (1982). The use of plasma triglyeride as a selection criterion in breeding leaner broilers, $24 \mathrm{th}$ British Poultry Breeders Roundtable Conference, Edinburgh (UK).

Gyles, N.R., A. Maeza and T.L. Goodwin (1982). Regression of Abdominal fat in broilers on abdominal fat in spent parents. Poultry Sct., $61: 1809-1814$.

Gyles, N.R., A. Maeza and T.L. Goodwin (1984). Regression of abdominal fat in broilers on abdominal fat in spent parents on severe feed restriction. Poultry Sci. $63: 1689-1694$

Leclereq, B., J.C. Blum and J.P. Boyer (1980). Selecting broiler for low or high abdominal fat : initial observations. British Poultry Sci. 21:107-113

Leenstra, F.R. (1984). Influence of diet and genotype on carcass quality in poultry and their consequences for selection. In : Recent Advances in Animal Nutri tion. pp. 3.16 Eds. W. Haresign and D.J.A. Cole, Butterworth, London, England. 
Pym, R.A.E. and A.J. Solvyns (1979). Selection for food conversion in broilers : Body composition of birds selected for inereased body weight gain, food consumption and food conversion ratio. British Poultry Sci. $20: 87-97$.

Ricard, F.M. and R. Rouvier (1967). Etude de la composition anatomique du poultet. I. Variabilité de la répartition des differentes parties corporelles chez des coquelets «Bresse-Pile». Ann. Zootech, $16: 23 \cdot 39$.

Ricard, F.H. and R. Rouvier (1969). Etude de la composition anatomique du poult. III. Variabilité de la répartition des parties corporelles dans une souch de type Cornish. Ann. Génét. Sél. Anim,, 1 : $151-165$.

Shebl, M.K.A. (1986). Genetic studies in poutry : Responses to individual and index selection for some economic traits in Alexandria chickens. Ph.D. Thesis. Faculty of Agric. Univ. of Alexandria.

Snedecor, G.W. and W.G. Cochran (1967. «Statistical Methodsi, 6th edn. Iowa State Univ. Press. Pullman.

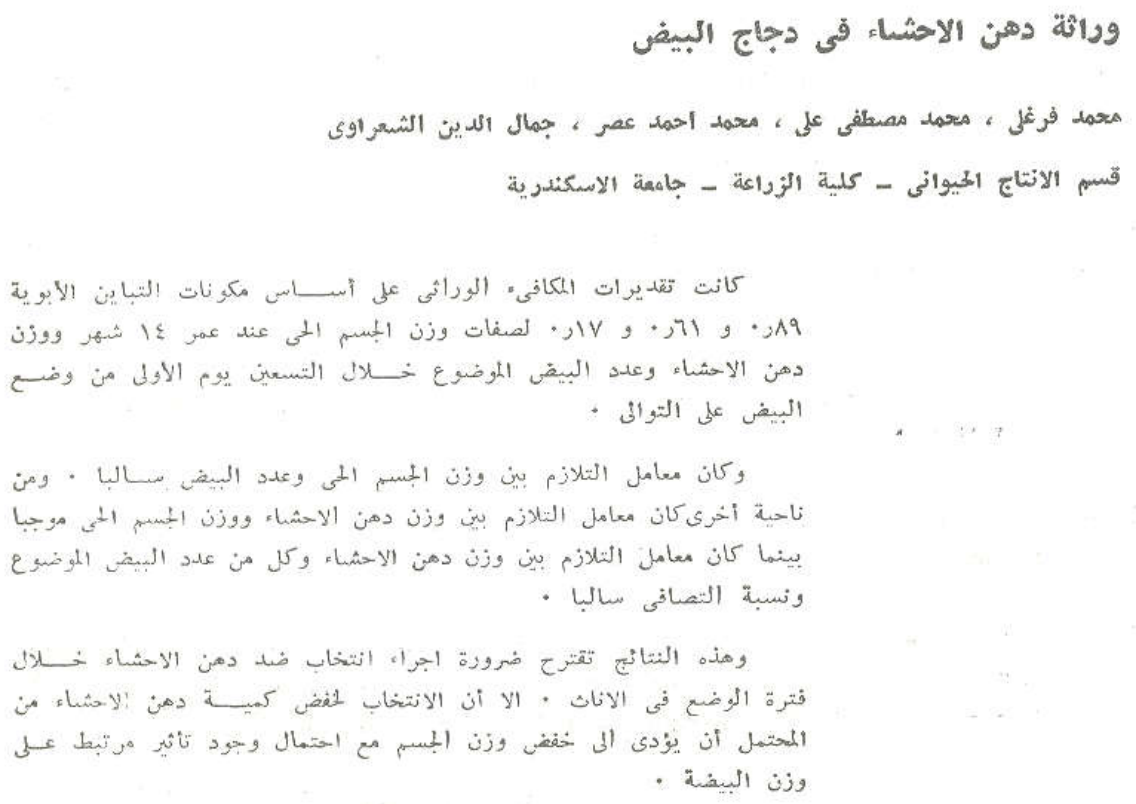

Egypt. J. Anim. Prod. 28, No. 1. (1986) 